\title{
Konrad Türst und seine Karte der Schweiz
}

\author{
Von Heinz Balmer
}

Das Mittelalter hatte den Erdkreis um Jerusalem angeordnet. Die Humanisten griffen auf Ptolemäus zurück. Von 1475 an jagten sich PtolemäusAusgaben, zuerst in Italien, 1482 bereits in Ulm. Das Gebiet der Schweiz war bei Ptolemäus karg bedacht. Diese Spärlichkeit weckte den Wunsch nach einer neuen Karte. Konrad Türst erfüllte diese Aufgabe.

\section{Türsts Leben}

Konrad Türst wurde um 1455 als unehelicher Sohn des Fraumünster Chorherrn Bernhard Türst in Zürich geboren. Beim Tode des Vaters erbte er 1480 das Haus zum Psalter. Er trug sich 1470 in Basel als Student ein, war auch in Ingolstadt (wo Mathematik und Astronomie gepflegt wurden) und promovierte am 29. Juli 1482 in Pavia zum Doktor der Medizin, kam nach Bern und wurde Mitglied der Zunft zum Distelzwang, deren Obmann Schultheiß Rudolf von ErLach war. Ihm widmete er auf Bestellung ein Büchlein mit Kalender und Gesundheitsregeln, «das schönste in deutscher Sprache abgefaßte schweizerische Gesundheitsregiment des 15. Jahrhunderts» (Bernhard Milt). Es schildert das von Erlach bekömmliche Klima, die geeignete Körperpflege, gibt Anweisungen über Essen und Schlafen, nennt Heilmittel bei Krankheiten und bietet eine Aderlaßtafel. Türst stützte sich auf Avicenna und Mesue, auf Galen und Hippokrates.

1485 kehrte er nach Zürich zurück, wo man ihn 1489 zum Stadtarzt wählte. Er heiratete eine Witwe Lienhart. Der bedeutende Arzt und Astronom Konrad Heingartner weihte ihn in die Kunst der Weissagung aus den Gestirnen ein. Für 1490 verfaßte Türst eine Prognostik für die Stadt und übereignete sie dem Großmünsterprobst Jаков von Cнам. Eine Voraussagung für 1491 widmete er dem Herzog von Mailand, Lodovico IL Mono, und erhielt dafür grüne Seidentücher. 1493 besuchte er Mailand und überreichte dem Herzog zwei Büchlein, in denen er die Schicksale der zwei kleinen Prinzen aus dem Stand der Gestirne bei ihrer Geburt vorhersagte. Auch diesmal bedankte sich der Herzog mit Seide. 
Vier medizinische Schriften Türsts entdeckte Bernhard Milt in der Zentralbibliothek Zürich (Gesnerus 1947, S. 27f.). Die umfangreichste stammt von 1495 und erteilt dem Abt von Rheinau, Johann Conrad von Grieshaim, der an Verdauungsstörungen litt, Ratschläge über Diät, Heilmittel und Lebenshaltung.

Zwischen 1495 und 1497 schuf Türst in Zürich sein Hauptwerk, eine Landkarte der zehnörtigen Eidgenossenschaft. Dazu gehörte eine Beschreibung, die er lateinisch und deutsch abfaßte. Er stellte von der Karte und vom Text mehrere Abschriften her. 1497 zog er wieder nach Mailand und brachte dem Herzog die Karte.

Türst suchte auch die Verbindung zu Kaiser Maximilian und verfaßte 1498 eine Genealogie des Hauses Habsburg. Dafür erhielt er schwarzen Samt. Maximilian berief ihn im Sommer 1499 als Leibarzt und Astrologen in seinen Dienst und versprach ihm auf zehn Jahre ein Jahresgehalt von 100 Gulden. Der Empfänger hoffte, seine Schulden zu tilgen; doch sein Leben währte nicht mehr lange. Am 12. Mai 1503 holte ein Bote für ihn in Innsbruck 50 Gulden ab. Am 18. August 1503 starb Türst in Zürich, seine Frau und die Kinder arm zurücklassend. Die Töchter Mechtild und Regula traten als Nonnen ins Kloster Frauental ein. Den wertvollen «schatz der bücheren» kaufte der Apotheker Anton Clauser für seinen Sohn Chrisторн, der später Stadtarzt von Zürich wurde. Bei ihm kamen die Bücher noch Conrad Gessner zustatten ${ }^{1}$.

\section{Die Handschriften von Türsts Karte und Beschreibung der Schweiz}

Die Landkarte besteht noch in zwei Exemplaren, in Wien und in Zürich. Bei beiden hat sich der Begleittext erhalten. Zum Wiener Exemplar ist er lateinisch, zum Zürcher Exemplar deutsch abgefaßt. Vom lateinischen Text kennt man drei weitere Exemplare ohne Karte. Sie befinden sich in der Preußischen Staatsbibliothek in Berlin, im Archiv des Grafen Ardua Sola in Mailand und in der Königlichen Bibliothek in Modena (nach Ischer).

Vom Schicksal der Handschriften weiß man folgendes. Die erste lateinische Niederschrift, «De situ Confoederatorum descriptio», war ursprünglich dem Rat von Bern zugedacht. Dann fand es Türst aussichtsreicher, sie

1 G.A. Wehrl, Der Zürcher Stadtarzt Dr.Christoph Clauser und seine Stellung zur Heilkunde im 16. Jahrhundert (Veröffentlichungen der Schweizerischen Gesellschaft für Geschichte der Medizin und der Naturwissenschaften, Band II), Zürich 1924. 
dem Kaiser Maximilian zu schenken. Heute steht sie in der Wiener Nationalbibliothek. Die zugehörige Karte trägt eingefügte lateinische Namen.

Die zweite lateinische Niederschrift wurde Lodovico IL Moro gebracht. Als Ludwig XII. von Frankreich 1499 in Mailand einrückte, betrachtete er die Bibliothek des Herzogs als Beute. Türsts Büchlein gelangte über Privatbesitz nach England und wurde 1882 von der Preußischen Staatsbibliothek erworben. Die Karte war verlorengegangen.

Eine dritte Ausfertigung ging an den Statthalter von Triest und befindet sich jetzt in Mailand.

Das deutsche Exemplar war dem Berner Altschultheißen Rudolf von Erlach gewidmet, für den Türst schon früher das Gesundheitsbüchlein verfaßt hatte. Karte und Schrift blieben fast 400 Jahre in der Erlachschen Bibliothek im Schloß Spiez aufgehoben. Im September 1875 wurde diese versteigert. Der Zürcher Kantonsrat und Industrielle HaNs WunderLYvon Muralt (bekannt durch seine Münzensammlung der alten Eidgenossenschaft) erwarb Karte und Text von Türst und zeigte sie dem Historiker Georg von Wyss, der 1879 darüber berichtete. Gerold Meyer von Knonau beschrieb im Jahrbuch des Schweizer Alpenclub 1883 die Karte eingehend. Georg von Wyss und Hermann Wartmann veröffentlichten Text und Karte in den Quellen zur Schweizer Geschichte, Band 6, Basel 1884. Der Anzeiger für schweizerische Geschichte brachte Nachträge über Türst. Zum Wort meldeten sich 1887 Rudolf Thommen, 1888 Theodor von Liebenau, 1898 Heinrich Türler, 1901 Albert Büchi, 1912 Friedrich Hegi. Trotzdem wäre das Original der Schweiz fast verlorengegangen. Als Wunderly 1921 starb, gelangte die Handschrift an einen Münchner Antiquar. Da kaufte sie Dr. Wilhelm Caspar Escher, der Präsident der Kreditanstalt, und schenkte sie am 11. November 1928 der Zentralbibliothek Zürich. 1939 erläuterte EDUARD Iмноғ die Karte als Vorlage zur ersten gedruckten Schweizerkarte von 1513, und 1945 legte TнеорніL Ischen eine sorgfältige zusammenfassende Studie vor ${ }^{2}$.

2 Dem Gesundheitsbüchlein erging es ähnlich. Es kam bei der Versteigerung von 1875 in den Besitz eines Berner Kunstsammlers. Nach dessen Tod erwarb es der Direktor des Schweizerischen Landesmuseums in Zürich, und wiederum aus dessen Nachlaß kaufte es die Zürcher Zentralbibliothek. Es wurde von ALFred Sснміd für die Herausgabe vorbereitet und von Erich Hintzsche 1947 in die Reihe der «Berner Beiträge zur Geschichte der Medizin und der Naturwissenschaften» aufgenommen. Eine Besprechung von Bernhard Milt findet sich im Gesnerus 1947, S. 61-63. Siehe auch im Gesnerus 1945, S. 161. 
Die geographische Zürcher Handschrift trägt die Signatur Ms Z XI 307. Das Büchlein besteht aus Pergamentblättern von 21,3 cm Breite und $15,5 \mathrm{~cm}$ Höhe. Der schön geschriebene Text beschlägt 20 Doppelseiten und endet auf Seite 21. Das Bändchen heißt Beschribung gemeiner Eydgnosschaft. Im prächtigen Anfangsbuchstaben ist das Wappen der von Erlach gemalt. Die Überschriften leuchten rot, die Anfangsbuchstaben der Abschnitte rot und blau, so daß sie die schwarzen Zeilen schmücken (siehe Abb. 2). Die Karte ist $56 \mathrm{~cm}$ breit und $42,2 \mathrm{~cm}$ hoch. Sie reicht Ost-West von Bregenz bis Lausanne, Nord-Süd von Säckingen bis Giornico. Süden ist oben. Die Karte wurde mit der Feder auf Pergament gezeichnet und bemalt: blau die Gewässer, grün die Berge, braun die Häuser und einzelne Felsen.

Eine Jahrzahl fehlt; doch konnte Thеорніц Ischer Karte und Begleittext aus Überlegungen datieren. Freiburg und Solothurn gehörten bereits zur Eidgenossenschaft, Basel noch nicht. Dieser Zustand dauerte von 1481 bis 1501. Der Empfänger, Rudolf von ERLACH (1449-1507), tritt als Altschultheiß auf. Er war es von 1495 bis 1500. Damit ist der Zeitraum bereits eng umgrenzt. Der Freiherr von Castelwart wird als Besitzer der Herrschaft Werdenberg erwähnt; er besaß sie 1493 bis 1498. Also beschränkt sich die Spanne auf 1495 bis 1498. Berns Schultheiß wird Matter genannt; er stand im Amt von Ostern 1495 bis 1497. Die Graubündner, die sich im Juni 1497 mit den Eidgenossen verbündeten, sind nirgends eingeführt. Der Begleittext muß zwischen Frühling 1495 und Frühling 1497 entstanden sein. Die Karte läßt erkennen, daß Türst den Weg über den Gotthard nach Mailand kannte; wirklich war er 1493 dort gewesen, und 1497 brachte er dem Herzog die Karte.

\section{Der Begleittext}

Bei Türsts Werk ist die Karte die Hauptsache. Die Beschreibung der zehn Orte bildet die erläuternde Begleitung, die die wichtigsten Namen geordnet aufzählt und nach der Vorschrift des Pтоцenäus Richtungen und Entfernungen angibt.

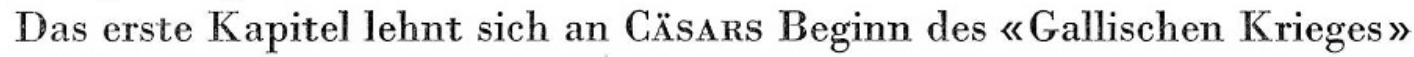
an. Schon Türst versuchte, die bei Ptolemäus bezeichneten Städte der Helvetier mit den Siedlungen seiner Zeit in Beziehung zu setzen. Irrtümlich deutete er Forum Tiberii als Solothurn, Gannodurum als Zürich.

Bei der Schilderung der zehn Orte zählt er jeweilen zuerst die geistlichen Herrschaften («der geistlichen eigenthum und sitz»), dann die weltlichen 
auf. Die Klöster, die Schlösser zogen ihn an. Wohl hebt er Weingärten, Wildgehege, Fischzuchten hervor, erwähnt die Bäder von Baden und Pfäfers und die Messen von Zurzach. Wichtiger aber war ihm die gegenseitige Lage der Orte. Seine Himmelsrichtungen sind:

Norden = «gegen mirternach», «gegem sibengestirn»,

Süden = «gegen mittem tag», «gegen der pfön» (Föhn),

Osten = «gegen der sunnen ufgang», "gegen ufgang»,

Westen = «gegen nidergang der sunnen»,

Nordosten = «gegen der byß» (Bise), "gegen dem schinttenhengst» (Schind-den-Hengst, ein anderes Wort für Bise). Im Aargau schreibt er «gegen der arbyß»(Aarbise).

Die Entfernungen der Ortschaften voneinander zählt er nach soundsoviel tausend Schritt, selten nach Roßläufen. Roßlauf war die Übersetzung des griechischen Wortes Stadion und bedeutete $185 \mathrm{~m}$. Türsts Berechnungen gründeten sich auf die Erfahrung der Wegstunden. Nach Eduard IмноF gehen seine Fehler bis zu $40 \%$ der Strecke, halten sich aber oft innerhalb $10 \%$.

\section{Türsts Karte}

\section{Ihr Inhalt}

Türst stellt das Gebiet der heutigen Schweiz dar, wie man es aus der Höhe über Basel in Richtung Südosten vor sich ausgebreitet sähe. Einige Randgebiete der heutigen Schweiz fehlen: Basel und die Ajoie im Norden, das Engadin im Osten, das Tessin südlich Biasca im Süden, Genf und die Waadt westlich Lausanne im Westen. Dafür sehen wir über den Bodensee hinaus in den Hegau, der Donau entlang bis Freidingen, den Neckar hinab bis Rottweil. Auch ein Stück Vorarlberg mit dem Lauf der Ill und dem Klostertal ist erfaßt. Im Südwesten tauchen als letzte Bilder Aosta und Novara auf, im Nordwesten gerade noch Pontarlier. Der Empfänger der Karte, Rudolf von ErLAch, hatte die Berner Truppen im Zug nach dem Hegau angeführt; die Darstellung jener Gegend mußte seine Teilnahme finden.

Das Blickfeld ist im Uhrzeigersinn um den Punkt Bern um $35^{\circ}$ gedreht, also die westliche Gegend nach Norden, die östliche nach Süden verschoben. Die Drehung kommt nicht von der damals östlichen Deklination der Magnet- 


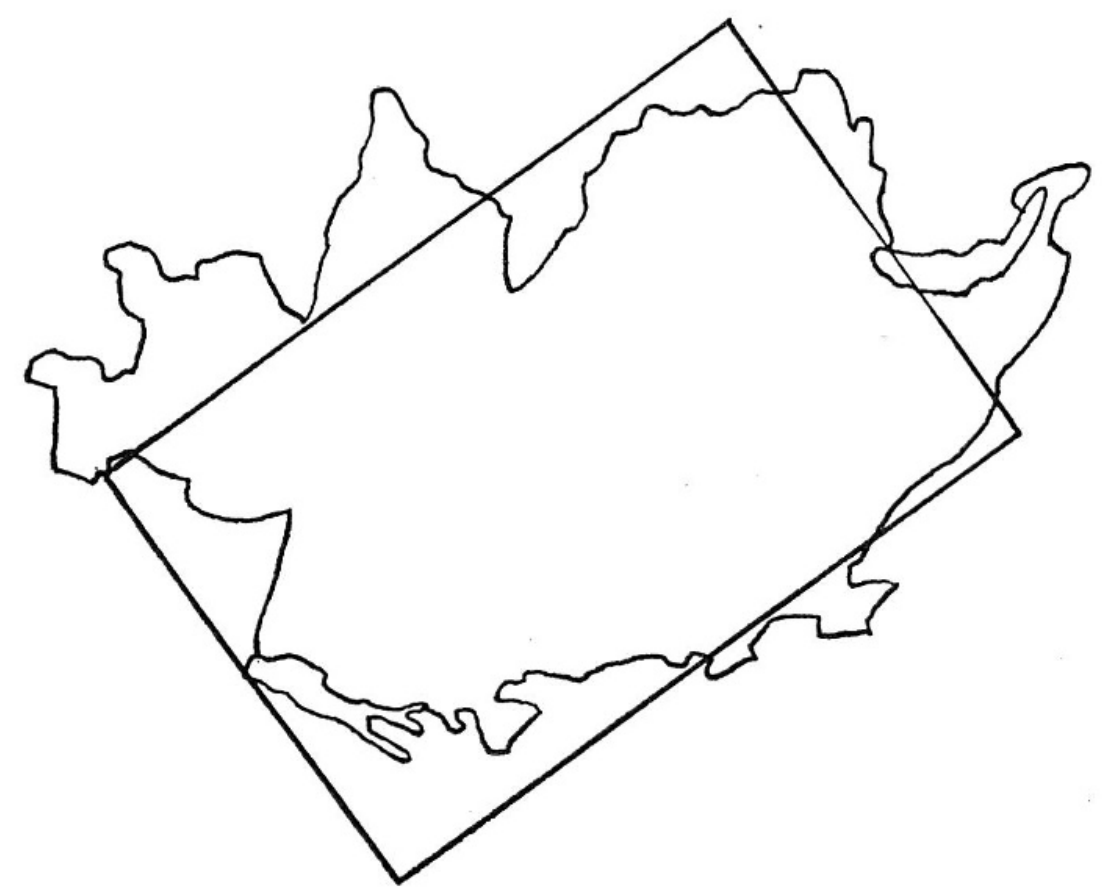

Abb. 1. Das Rechteck zeigt ungefähr das Blickfeld Türsts auf dem heutigen Umriß der Schweiz. Süden ist oben

nadel her, die eine Drehung von wenigen Grad, und zwar gerade im Gegensinne, bewirkt hätte.

Am reichhaltigsten ist die Karte längs dem Rhein von Chur bis Säckingen, in der Gegend der Thur, Limmat, Reuß und Aare, also um Schaffhausen, Zürich, Zug, Luzern, Aarau und Solothurn. Die Karte enthält 521 Namen; Schlösser und Klöster, Städte und Dörfer sind vor allem genannt. Nach Meyer von Knonau entfallen 201 auf die zehn Orte, 100 auf übrige schweizerische Landstriche, 220 auf Rhätien, Wallis und Schwaben. Ins Gebiet Berns (wozu in der Waadt damals Aigle, Bex und Villeneuve gehörten) zielen 74 Namen; 36 betreffen Zürich, 24 Uri, das von Seelisberg bis Giornico reichte. Im Kanton Zürich sind außer der Hauptstadt 17 Schlösser, 4. Gotteshäuser, 3 Städtchen und 9 Dörfer bezeichnet. Auch Thurgau, Aargau und der Hegau sind reich mit Schlössern und Klöstern ausgestattet. In Nidwalden stehen Stans und Beckenried, in Obwalden Alpnach, Sarnen, Sachseln, «Bruder Claus». In Schwyz wird das Muottatal, in Uri das Schächental mit Bürglen genannt. Im Jura liegen die Schlösser Valangin, Falkenstein, Bechburg und Schenkenberg an der Lägern. Solothurn soll zwei Roßläufe, Freiburg 22 Meilen vom Jura entfernt sein. 


\section{Die Darstellungsmittel}

Die Karte ist ein Vogelschaubild mit Bergen, Wäldern, Ortschaften, Flüssen und Seen. Der Vordergrund scheint vergrößert, der Hintergrund verkleinert; die ferne Poebene verschwimmt in flachen Pinselstrichen. Die grün bemalten Berge haben auf der Ostseite Schatten und enthalten im Berner Oberland braune Felswände. Nadel- und Laubbaumreihen sind in waldigen Gegenden an freien Kartenstellen eingestreut. Die Ortschaften wurden als kleine Ansichtsbilder hingezeichnet; etwas Ausgeprägtes ist dabei festgehalten. Diese Siedlungsbildchen - oft die frühesten vorhandenen - geben der Karte besondern Reiz. Grenzen und Straßen fehlen; doch hielt Türst die Brücken fest. Wie diese Übergänge über die Flüsse erkennt man auch die Übergänge über die Berge, weil Türst die Orte längs den Paßstraßen aufreiht. Am deutlichsten wird dies am Gotthardweg.

Die Karte ist hübsch, übersichtlich, von einem begabten Zeichner gemalt. Wenn er die Dörfer durch ein schlichtes Holzhaus oder eine Kirche bezeichnet, die Städte aber mit ihren Mauern und Türmen darstellt, gewinnt der Betrachter den richtigen Maßstab. Der Standort stimmt fast immer. Das Gewässernetz ist klar. In frei erfundenen Schwüngen, die naturgetreu wirken, durchmessen die Flüsse die Landschaft. Türst mußte die Karte aus dem Eigenen nehmen; sie trägt den Ausdruck seiner Persönlichkeit.

\section{Die Orientierung}

Der Blick richtet sich nach Süden, gegen die Alpen. Dabei folgte Türst nicht Ptolemäus, sondern tat das für die Schweiz Natürliche. Doch stellte er sich nicht genau südwärts, sondern so, daß die beiden großen Seen, die die Schweiz gegen Sonnenaufgang und Sonnenuntergang begrenzen, ihm gleichmäßig zur Linken und zur Rechten standen. Der Bodensee, der nördlicher als der Genfersee läge, wird auf dessen Breite gebracht. Auch die Karte des Cusanus (erschienen 1491) und die des Hartmann Schedel (1493) hatten im weitern Überblick das Land so gedreht, und selbst Aegidius Tschudi hat 1538 sein Bild der Schweiz noch zwischen die Seen gestellt. St. Gallen liegt in Türsts Karte fast auf der Breite von Sitten. Die Drehung hatte für ihn die günstige Folge, daß sich das den Eidgenossen zugewandte Rottweil ohne großen Zwang auf die Karte heranholen ließ, während das mehr im Westen liegende Basel außer den Rand fallen und weggelassen werden durfte, da es noch nicht eidgenössisch war. 
Schuld an der Drehung war wohl der Verlauf der vordersten Jurakette. Man war sich nicht klar, wie schräg sie im Gradnetz der Erde stand, und neigte dazu, sie als Ost-West-Gebirgszug aufzufassen.

\section{Der Maßstab}

Eduard Imнof maß 30 größere Entfernungen, wobei er Ost-West- und Nord-Süd-Strecken auseinanderhielt. Er gewann als Mittel für den OstWest-Maßstab 1:470000 im Vordergrund, 1:570000 im alpinen, südlicheren Hintergrund. Als Nord-Süd-Maßstab fand er im Vordergrund 1:510000, im Hintergrund 1:560000. Das Alpengebiet ist somit kleiner dargestellt als das Mittelland. Der Vordergrund ist nach links und rechts gedehnt, weniger nach oben. Das Entferntere erscheint verkleinert; das Blickfeld umfaßt dort eine größere Weite.

\section{Das Gradnetz}

Am Rand hat Türst ein Gradnetz eingetragen. Damit erweist er (im Gegensatz zu Tschudi) seine mathematische Ader. Den Abstand von Grad zu Grad, der 3600 Sekunden beträgt, teilte er in neun gleiche Abschnitte von 400 Sekunden oder 6 Minuten 40 Sekunden. Die Zählung schreitet daher von einem Grad zum andern über folgende acht Stufen: $6^{\prime} 40^{\prime \prime}-13^{\prime} 20^{\prime \prime}-20^{\prime}-26^{\prime} 40^{\prime \prime}-33^{\prime} 20^{\prime \prime}-40^{\prime}-46^{\prime} 40^{\prime \prime}-53^{\prime} 20^{\prime \prime}$.

Die Breiten stehen links gleich wie rechts am Kartenrande. Sie beginnen oben (im Süden) mit $45^{\circ} 20^{\prime}$ und reichen bis zu $47^{\circ} 40^{\prime}$ am untern Rande.

Die Meridiane sind oben und unten verschieden bezeichnet, indem sie nämlich am unteren, nördlichen Rande dichter geschart sind als oben. Sie würden, wenn man sie über das Kartenblatt zöge, gegen unten, also nordwärts, näher zusammentreten. Türst wußte, daß die Meridianabstände polwärts enger werden. Doch übertrieb er dies. Die beiden äußersten Meridiane bilden bei ihm einen Winkel von etwa $10^{\circ}$, während er nur $2,5^{\circ}$ betragen sollte (Імноғ).

Im Süden sind die Meridiane von $25^{\circ} 46^{\prime} 40^{\prime \prime}$ bis zu $29^{\circ} 20^{\prime}$ gezählt, im Norden von $25^{\circ} 26^{\prime} 40^{\prime \prime}$ bis zu $29^{\circ} 40^{\prime}$; es sind also im Vordergrund auf beiden Seiten je drei Einteilungsstufen mehr enthalten, im ganzen $40^{\prime}$ mehr als im Süden. Da diese Zusammenziehung der Meridiane stärker angenommen ist, als sie in Wirklichkeit wäre, sollte der Vordergrund sich als stärker verkleinert erweisen als das Alpengebiet. Doch bestanden damals viel zuwenig Breiten- und Längenbestimmungen, als daß Türst seine Karte wirk- 
lich in das Netz hätte passen können. Wir sahen ja, daß sein ganzes Blickfeld eine Drehung aufweist, die ihm nicht bewußt gewesen sein kann. Er hatte offenbar noch keine Magnetnadel. Den Vordergrund zeichnete er viel gedehnter, als dem Netz entsprochen hätte, den Hintergrund dagegen kleiner. Die Nord-Süd-Ausdehnung geriet überall weiter, als das Netz sie verlangt hätte.

Die Länge und Breite, unter denen Türst einen bestimmten Ort eintrug, lassen sich ablesen, indem man ein Lineal durch diesen Ort legt und nach den zwei gleichen Zahlen der einander gegenüberliegenden Kartenränder richtet. So findet man, daß Bern beim 47. Breitengrad und auf $26^{\circ} 26^{\prime} 40^{\prime \prime}$ östlicher Länge liegt. Auf Thомаs Sснӧрғs Berner Karte von 1578 hat Bern dagegen eine östliche Länge von $29^{\circ} 10^{\prime}$.

Hier stellt sich die Frage, von welchem Meridian aus gezählt wurde. In der Zwischenzeit von Türst zu Schöpf war der Stille Ozean entdeckt worden. Pтоlemäus hatte die Meridiane über Europa zu dicht gezählt. Jetzt mußte das Netz noch den Stillen Ozean überspannen; die Zwischenräume der Maschen wurden über Europa erweitert. Daher sollte, wenn Türst und Schöpf denselben Ausgangsmeridian gewählt hätten, Schöpfs Längenzahl für Bern geringer sein. Es ist aber umgekehrt. Somit muß sich Türsts Netz auf einen näheren, Schöpfs Netz auf einen ferneren Ausgangsort beziehen.

Zürich liegt bei Türst auf dem 28. Meridian. Es schließt mit Bern einen Längenunterschied von $1^{\circ} 33^{\prime} 20^{\prime \prime}$ ein, daß heißt $5600^{\prime \prime}$. Nach heutiger Ermittlung beträgt dieser Unterschied nur wenig über $1^{\circ}\left(3824^{\prime \prime}\right)$. Doch liegt bei Türst Zürich genau östlich statt nordöstlich von Bern, und so scheint der Meridianabstand größer. Die Luftlinie Bern-Zürich mißt $95 \mathrm{~km}$, und zwar sowohl nach der neuen wie nach Türsts Karte, wenn man deren mittleren Maßstab 1:500000 nimmt. Gesetzt, bei Türst seien $5600^{\prime \prime}=95 \mathrm{~km}$, so enthält $1^{\prime \prime}=17 \mathrm{~m}$ und $1^{\circ}=61,2 \mathrm{~km}$. Der Ausgangsmeridian wäre $28^{\circ}$ oder 1713,6 km westlich von Zürich zu suchen, bei den Kanarischen Inseln. Indessen scheinen solche Rechnungen unsicher.

Імноғ meint, Türst benütze den Ausgangsmeridian von Ferro und gebe Berns Länge um $1^{\circ} 20^{\prime}$ zu groß an. Es wurde jedoch erst später üblich, die Längenzählung bei jener westlichsten der Kanarischen Inseln zu beginnen. Wahrscheinlich zählte Türst von der größten Insel jener Gruppe aus, von Teneriffa, während Schöpf vielleicht von den Kapverdischen Inseln ausging.

Ptolemäus selber hatte die Mittagskreise von der Gesamtheit der Kanarischen Inseln aus gezählt, die als letzte Landmarken im Westen erschaut waren. Er nannte jene Inseln Fortunatae (die Glückseligen) und 
ordnete sie in Nord-Süd-Richtung an. Die Humanisten sahen sich vor neue Entscheidungen gestellt: Azoren-, Kapverden- und Kanaren-Inseln standen in mancherlei Entfernungen zur Wahl. Zudem bewirkte die wankende Längenbestimmung, daß selbst über die Neuausgaben der Ptolemäus-Weltkarte die Netze verschieden gezogen sind. Die Frage bleibt offen, an welche Vorbilder sich Türst und Schöpf anlehnten.

\section{Das Verzerrungsgitter}

Eduard Imнof hat mit Hilfe heutiger Karten einige Längen- und Breitenkreise in Türsts Bild eingetragen, und zwar die Breitenkreise von $46^{\circ}$ bis $48^{\circ}$ und die Meridiane von $24 \frac{1}{2^{\circ}}$ bis $27^{1 / 2^{\circ}}$ östlich Ferro, stets in Abständen von halben Graden fortschreitend, so daß er ein Gitter aus fünf Querund sieben Steillinien erhielt. Es verlief schräg von links oben nach rechts unten, zeigte also die Verdrehung, und außerdem ergaben die Steillinien eine Verdichtung in der rechten, westlichen Kartenhälfte. Die Ostschweiz hatte Türst also größer gezeichnet als die Westschweiz. In Bünden und Wallis wurden die starken Verzerrungen deutlich.

Man darf ebensogut die Meridiane von östlich Greenwich eintragen und erhält ein ähnliches Verzerrungsgitter. Der Meridian $9 \frac{1}{2}{ }^{\circ}$ östlich Greenwich verläuft bei Meersburg-Rorschach-Appenzell-Maienfeld, jener von $8 \%^{1 / 2^{\circ}}$ bei Stuhlingen-Eglisau-Zürich-Kappel-Cham-Beckenried-Hospenthal, jener von $7 \frac{1}{2}{ }^{\circ}$ bei Solothurn-Fraubrunnen-Bern-Erlenbach-Siders. Das Wallis erweist sich als nach Osten verschoben. Der 47. Breitenkreis bewegt sich aus der Gegend von Maienfeld über die Linth nach Brunnen, an Sumiswald vorbei und zwischen Signau und Burgdorf, dann zwischen Bern und Münchenbuchsee nach Neuenburg. Zuweilen ergeben sich Streupunkte (Luzern, Weggis, Küsnacht), aus denen man das Mittel der Beziehung nehmen muß.

Berns Breite ist bei Türst am richtigsten getroffen; auch hat Bern am ehesten die wahre Länge östlich der Kanaren, und die Himmelsrichtungen sind um Bern am wenigsten verdreht. Імноғ schließt: «Bern erscheint somit als der feste Pol der Karte, als der geographisch am besten bestimmte Punkt, um den sich dann alles übrige angegliedert hat. » Das Netz am Rande scheint auf Bern bezogen. Ob Türst selber, oder wer so früh schon in Bern die Breite bestimmt hat, ist nicht bekannt. In Türsts Karte bezieht Bern als erster Ort der Eidgenossenschaft hinsichtlich der geographischen Breite einen dauernden Platz. 


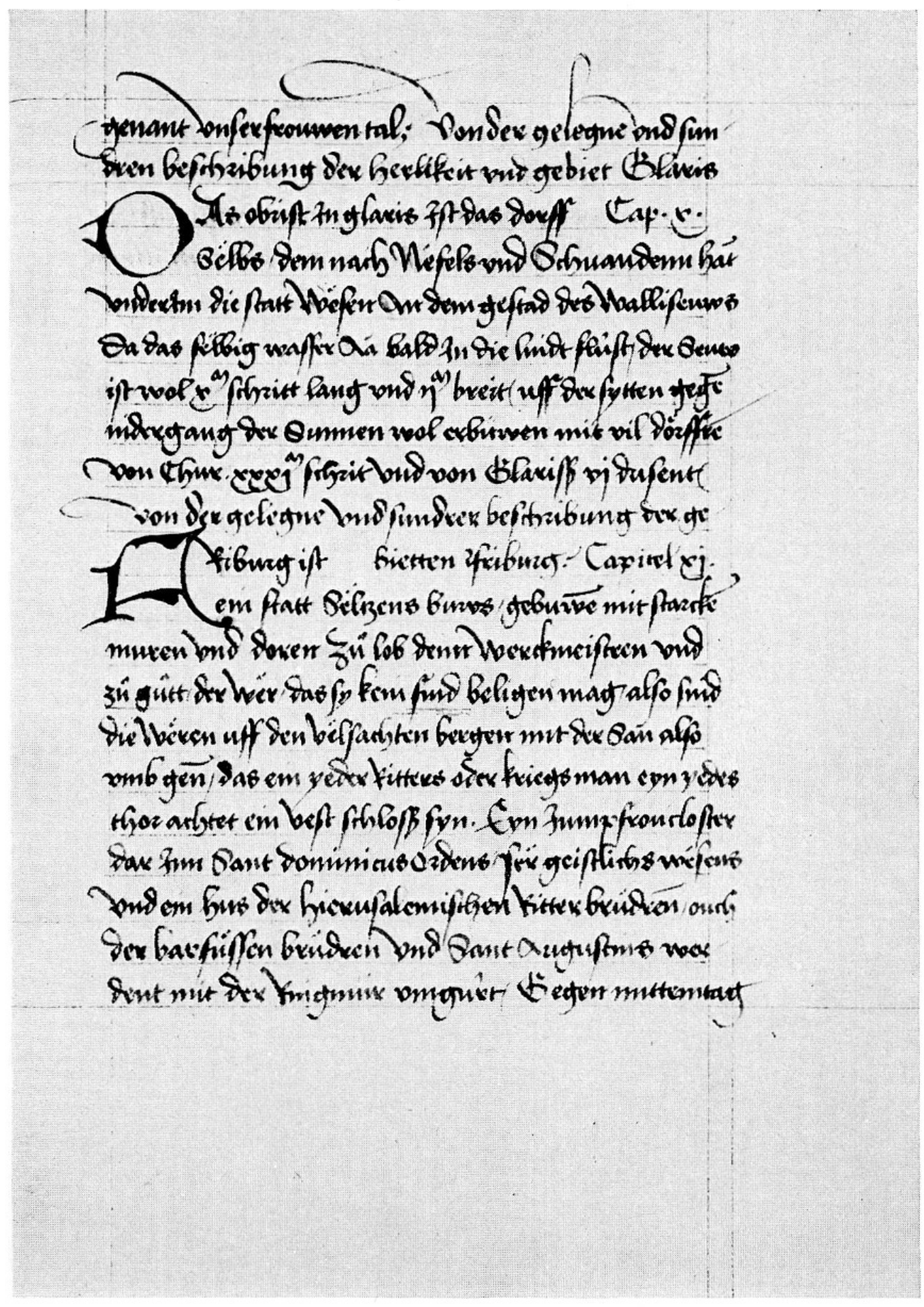

Abb. 2. Seite 15 aus Konrad Türsts Beschribung gemeiner Eydgnosschaft in der Zürcher Zentralbibliothek (nat.Gr.). Die Seite enthält zwei rote Überschriften. Die eine beginnt mitten in der obersten Zeile: «Von der gelegne vnd sundren beschribung der Herlikeit vnd gebiet Glaris. Cap. X»; die andere steht in der Mitte der Seite: «Von der gelegne vnd sundrer beschribung der gebietten Friburg. Capitel XI» 


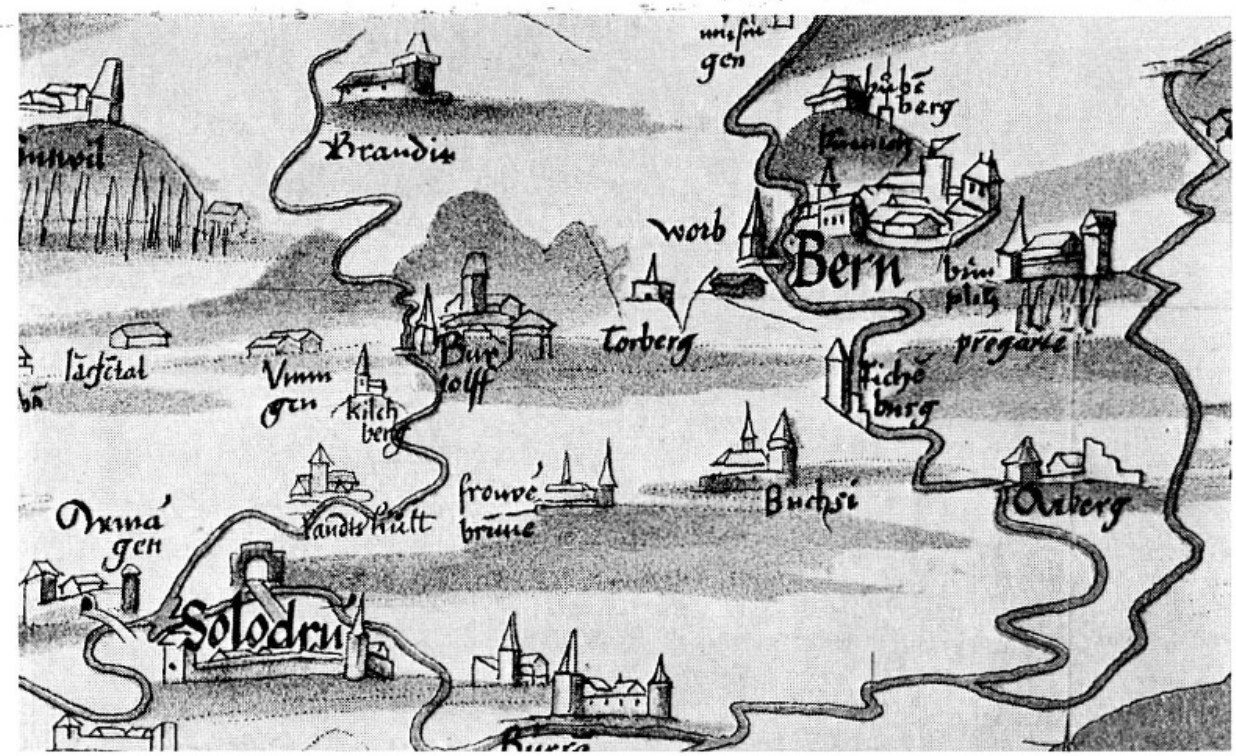

Abb. 3. Ausschnitt aus Konrad Türsts Karte der Eidgenossenschaft. Naturgetreue Einzelheiten in den Ortsbildchen: Bern mit Rathaus, Kran auf dem Münsterturm, Nydeggkirche und Stadttor jenseits der Aare. Links die Emme, rechts die Saane als Aarezuflüsse. Kirchberg mit der Kirche auf der Anhöhe. Ob Büren die Wallfahrtskirche. Bümpliz mit dem Schloß der von Erlach

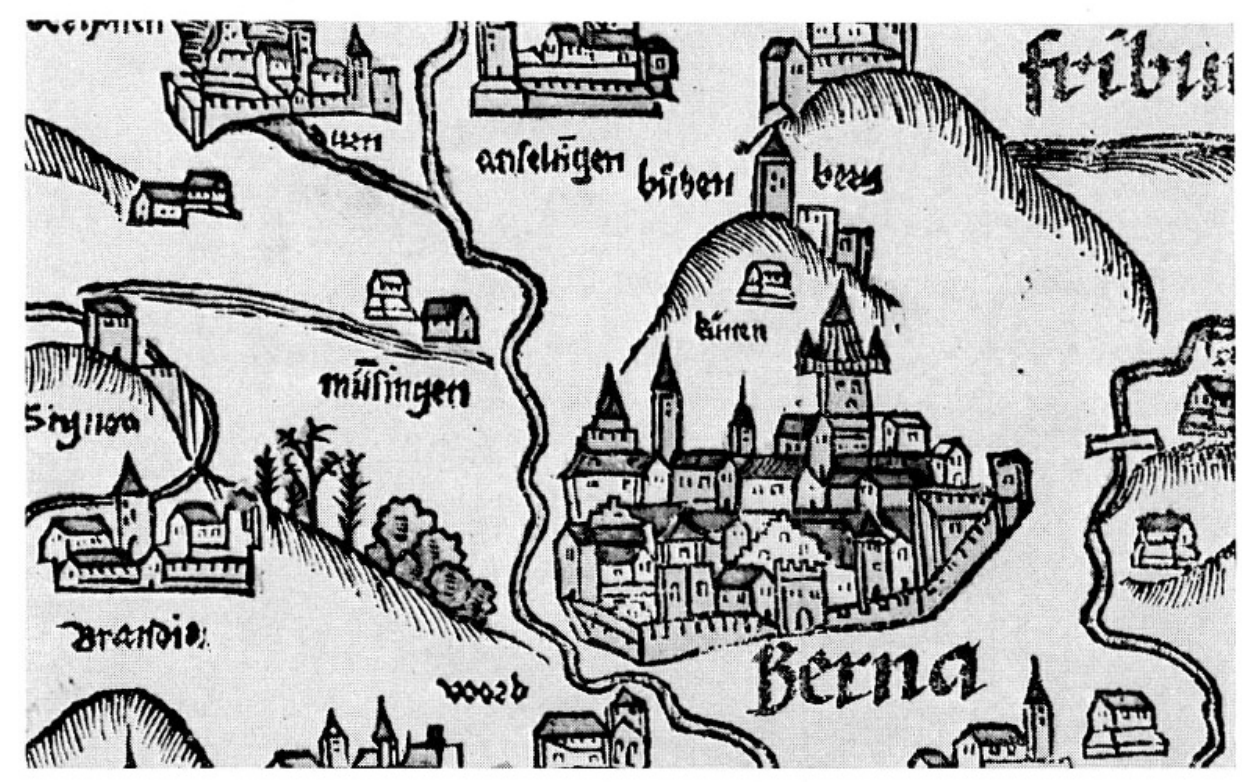

Abb. 4. Ausschnitt aus der «Tabula nova Heremi Helvetiorum» der Straßburger Ptolemäus-Ausgabe von 1513. Diese Karte geht auf Türsts Vorlage zurïck; aber die Ortsbilder sind vom Holzschneider willkürlich verändert worden 


\section{Alte Namen}

Bald fallen in der Karte Namen auf, die nicht mehr gebräuchlich sind. In romanischen Gebieten verwendete Türst deutsche Bezeichnungen. Oerielsß, Glattifer, Pfeud, Irnes - so hießen Airolo, Piottino, Faido, Giornico. Das erinnert an die Urner Herrschaft im Livinental, die von 1441 bis 1798 dauerte. 1478 wollte Herzog Galeazzo Maria Sforza von Mailand die Leventina zurückerobern, wurde aber bei Giornico geschlagen. Seither war Irnes (bei Tschudi Yrnis) als Grenzpunkt berühmt.

Das Tessin reicht bei Türst nicht weiter. Aber bei Tschud 1538 und Johannes StumpF (der seine Schweizer Chronik 1548 mit Ausschnitten nach Tschudis Karte schmückte) lesen wir weiter Bellentz, Luggaris, Lowertz, Chum - für Bellinzona, Locarno, Lugano, Como. Sowohl Türst wie Tschudi und Stumpf nennen Domodossola Thum. Es war der Hauptort des Eschentales, das den Eidgenossen die langen Eschenspieße lieferte und das sie seit 1410 mehrmals erobert, aber immer wieder verloren hatten. Die bei Tschudi neu hinzutretenden Namen sind Zeugen der seit Türst verflossenen Geschichte: 1500 geriet Lodovico il Moro in französische Gefangenschaft; Bellinzona gehörte seit 1501 Uri, Schwyz und Nidwalden, und 1512 eroberten die Eidgenossen Locarno, Lugano und nochmals Domodossola. Das Eschental mußten sie 1515 wieder preisgeben; aber Locarno und Lugano wurden Landvogteien, und der Bischof von Como war zinspflichtig. Durch die Kriegszüge und die gemeinen Herrschaften wurden die Ortsnamen eingedeutscht und diesseits der Alpen geläufig.

Aber auch viele Orte der Westschweiz, die heute meist französisch benannt werden, trugen deutsche Namen. Im Gebiet zwischen Neuenburgersee und Saane läßt sich die seitherige Verschiebung der Sprachgrenze nach Osten verfolgen. Statt Avenches, Payerne, Estavayer und Romont sagte man Wiflisburg, Peterlingen, Stäfis und Remund. Dies belegen Türst und Tschudi. Hauterive hieß bei Türst Altenriff (so auch noch 1668 auf der Freiburger Karte des Franz Peter von der Weid).

Für die Reihe der Namen vom Genfersee ins Rhonetal - Vevey, Villeneuve, Aigle, Bex, St.Maurice, Martigny - lesen wir bei Türst: Vivis, Nuwstatt, Besß, Elen, S.Maritz, Martinach. (Aigle und Bex haben bei ihm Platz getauscht.) Tschudi schreibt: Vivis, Neuwenstatt, Aelen, S.Mauritz, Martenach. Bex war seit 1464, Aigle seit 1475 bernisch. Der Mont Jorat, das Bergland der Waadt bei Lausanne, heißt bei Türst Jurthen.

Seltener zieht Türst statt der deutschen eine lateinische Form heran. 
Am Gotthard schreibt er, Ptolemäus folgend, das Wort Adula und setzt nur klein Gotzhart darunter.

Das kleine w wird von Türst meist wie zwei uu geschrieben. U und V wechseln beliebig (Dauetsch $=$ Tavetsch, Vstri $=$ Uster). Das über einen Selbstlaut gesetzte waagrechte oder aufsteigende Strichlein drückt ein nachfolgendes $\mathrm{N}$ aus. Dabei ahmte man das Lateinische nach, wo es ein $\mathrm{M}$ bedeutete. Auch auf den Karten von Aegidius Tschudi, Sebastian Münster, Johannes Stumpf, Joost Murer, Gerhard Mercator ist das Strichlein verwendet. Beim Abschreiben der Ortsnamen habe ich diese Feinheiten übergangen.

\section{Türsts Fehler}

Am Vierwaldstättersee ist der Kreuztrichter sichtbar; dann aber fehlt die Unterscheidung der drei Becken, indem die zwei engen Stellen nicht angedeutet sind und der Urnersee nicht abgewinkelt wird. Der See krümmt sich von Luzern als einzige Sichel zuerst nach Süden, dann nach Osten, während er zuerst in zwei versetzten Becken nach Osten und dann im Knick nach Süden gehen sollte.

Der Lungernsee ist zu groß gezeichnet, ebenso der Murtensee, der größer als der Bielersee und abflußlos dargestellt ist, weil die Broye fehlt.

Der Winkel, den die Längsachsen von Thuner- und Brienzersee miteinander einschließen, ist zu flach $\left(147\right.$ statt $\left.115^{\circ}\right)$. Die Längsachse des Thunersees zielt nach Bern, die des Brienzersees nach Freiburg, während in Wirklichkeit die verlängerte Achse des Thunersees mitten zwischen Bern und Freiburg trifft und die des Brienzersees sogar nach Aigle und Seelisberg gerichtet ist. Den Thunersee hätte Türst um $21^{\circ}$, den Brienzersee um $53^{\circ}$ im Gegenuhrzeigersinn drehen sollen.

Nach der Betrachtung der Seen wenden wir uns den Flüssen zu. Der Vorderrhein entspringt nicht am Gotthard, sondern fließt vom obern Blattrand bis Chur viel zu sehr von Süden her, aus der Richtung, wo Bellinzona wäre. Der Oberlauf des Rheins und des Ticino würden bei Bellinzona fast einen rechten Winkel einschließen, wobei der Rhein vom Angelpunkt hinweg und der Tessin darauf zufließt. In Wirklichkeit entspringt der Tessin erst südlich des Vorderrheins, und die beiden Flüsse bilden, von ihren Quellen wegströmend, einen Winkel von $60^{\circ}$ gegen Westen. Von Chur und Zizers bis Vaduz und Werdenberg läßt Türst den Rhein eine übermäßige Schlinge nach Westen durchlaufen; er hatte darin viele Namen unterzubringen. Vom Prätigau deutete er nur den Ausgang an. 
Die Entwässerung der Nordostschweiz besorgen in Wirklichkeit die aus dem Zürichsee zur Aare strömende Limmat, die aus dem Greifensee zum Rhein fließende Glatt, die Töß bei Winterthur und die Thur aus dem Toggenburg. Türst läßt nur die Töß weg. Die Glatt stimmt bis an den Unterlauf. Regensberg liegt zutreffend westlich der Glatt. Dann sollte diese bei Eglisau den Rhein erreichen. Um Regensberg herum aber biegt sie nach Westen und mündet zwischen Baden und Klingnau in die Limmat. In Wahrheit flösse dort der Limmat die Surb zu; die Glatt wurde hier damit verwechselt.

Türst kannte die Namen Obersimmental, Niedersimmental und Erlenbach und hielt sie für drei Dörfer. Den Fluß Simme kannte er nicht und ließ das Simmental weg. «Erlibach» versetzte er an die Kander. «Obersibental» und «Nidersibental» erscheinen als Dörfer an der Saane. Die «San entspringt» bei Saanen; dann fließt sie vorbei an Obersibental, Nidersibental, Altenriff, Friburg, Loupen, die alle an ihrem Westufer erbaut sind, und mündet unterhalb (statt oberhalb) «Arberg" in die Aare (siehe Abb.3). Die Sense fehlt.

Im Berner Oberland zeichnet Türst das Kandertal. Seine Kander beginnt im Dorfe Kander, geht über Frutigen, Erlenbach und Steffisburg, das hinter Spiez versetzt ist, und mündet zwischen Thun und Amsoldingen in die Aare. (Der Kanderdurchstich zum Thunersee wurde erst 1711-1714 vollzogen.) Die Täler der Lütschine fehlen, ebenso das Haslital. Dicht hinter dem obern Ende des Brienzersees erhebt sich ein Gebirgsstock, von dem die «Ar» in kurzem Lauf, aber in richtiger Biegung herniedereilt. Die Bezeichnungen des Haslitales sind an das begangene Ufer des Brienzersees heruntergerutscht. Oben am See liegt Guttannen, bei der Seemitte Hasle; auch hier hielt Türst den Namen der Talschaft für ein Dorf. Am untern Ende des Sees folgt Brienz; ihm gegenüber liegt Trachselwald. Im Emmental fehlt dieser Ort; er wurde mit Iseltwald verwechselt. Grimsel und Furka («Furgen ») sind an richtiger Stelle zwischen Guttannen und Realp genannt.

Die Emme entspringt namenlos bei Brandis (siehe Abb. 3). Sumiswald und Trub haben keinen Fluß; doch beginnt dahinter das «Emmentall» als Fluß nach Luzern. Gemeint ist das Entlebuch mit der Kleinen Emme. An dem Fluß steht keine Ortschaft; das Entlebuch ist leer.

Die Orte finden sich meistens, aber nicht immer auf der richtigen Seite der Flüsse. Fiesch, Raron und Sitten liegen südlich statt nördlich der Rhone, Brig dagegen nördlich statt südlich. Das naturgetreu abgebildete Schloß Hohentrins, das am Vorderrhein zwischen Ilanz und Ems steht, er- 
hebt sich rechts statt links am Fluß. Hohenems und Dornbirn («Dorrenbürren») setzt Türst von der vorarlbergischen auf die schweizerische Seite des Rheins. Nidau liegt am untern Ende, aber auf der Juraseite des Bielersees; Biel selber ist ziemlich weit vom See entfernt.

Das Bernerland war Türst, als er in Zürich zeichnete, von seinem frühern Aufenthalt her nicht mehr ganz gegenwärtig. Seine Fehler sind erheiternd. Im ganzen war diese künstlerisch hingeschwungene Karte ein unbekümmerter Weitwurf. Es bedurfte einer kühn ausgreifenden Hand, damit der Schleier, der das Land bisher verborgen hielt, zerriß.

\section{Flüsse und Brücken}

Selbst schwierigere Flußverhältnisse hat Türst oft treffend wiedergegeben, besonders in der nähern Umgebung von Zürich. Der Pfäffikersee ist richtig mit dem Greifensee verbunden. Die Linth fließt oben in den Zürichsee; dort erstreckt sich auch der jetzt verschwundene Tuggenersee. Bei der Holzbrücke ob Schännis empfängt die Linth von Osten den Zufluß aus dem Wallensee. Weiter hinten bei Schwanden ist die Gabelung dargestellt, wo Sernf und Linth sich treffen. Die Lorze erreicht zwischen Zug und Cham richtig den Zugersee und verläßt ihn bald wieder, um dann in die Reuß zu münden, die von der andern Seite her bereits die Kleine Emme aufgenommen hat. Beim Oberlauf der Reuß ist auch der Bach des Schächentals gezeichnet.

Gut wiedergegeben sind die Flüsse im Aargau. Wo die Aare dem Jurafuße entlangstreicht, empfängt sie zwischen Emme und Reuß aus dem Sempachersee die Suhr, aus dem Baldegger- und Hallwilersee die Hallwiler Aa. Die kleineren Zuflüsse wie Langeten und Wigger sind weggelassen.

Angeschrieben sind die Flüsse stets bei ihrer Quelle. Bei Vorder- wie Hinterrhein steht «Rhin». Von den Zuflüssen des Rheins sind benannt: Lanquart, Ill, Dur (Thur), Ar (Aare), Birs und Necker (Neckar). Von den Zuflüssen der Aare sind vermerkt: Cander, San, Zil, Rhüß. Ferner liest man Lint (Lindt) und Loretz (Lorze). Die Lindmag (Limmat) benannte er nur im Text, nicht auf der Karte. Die Rhone heißt Rhotten, der Ticino Tisin, die Donau Thünaw.

Die Brücken sind als Schlüsselpunkte sorgfältig eingetragen. Wir erblicken die oberste Rheinbrücke, wo Vorder- und Hinterrhein sich treffen; es wäre die von Reichenau. Weiter sehen wir die Brücken von Konstanz, 
Stein am Rhein, Dießenhofen und Laufenburg. Die Aare überschritt man in Thun, Bern, Aarberg, Solothurn, Aarwangen, Aarau und Brugg. Über die Reuß spannten sich im Oberlauf die Teufelsbrücke bei Göschenen, im Unterlauf die Brücken von Bremgarten und von Mellingen. Über die Thur führten die Brücken bei Schwarzenbach und Andelfingen. Die Linth überquerte man auf der gedeckten Holzbrücke von Ziegelbrücke (die seit 1451 erwähnt wird). Sichtbar sind ferner der Damm von Rapperswil, die Emmenbrücke bei Burgdorf, der Saaneübergang bei Laupen. Eine Rhonebrücke ist unterhalb St.Maurice gezeichnet, ebenso die Brücke über den Tessin bei Giornico. Für eine schweizerische Brückengeschichte liefert Türst Stoff. Einzelne Brücken hat er näher angedeutet: die von Reichenau ist auf hohe Stützen gestellt, die von Aarwangen gewölbt, die von Giornico mit Pfeilern an den Enden versehen. Bei Solothurn, Aarwangen, Brugg und St.Maurice gewahrt man die Brückentore. (Für die Berner Nydeggbrücke, die Brücken bei Laupen und Burgdorf, Solothurn und Aarwangen siehe Abb. 3.)

\section{Berge}

Türst verbindet die Berge nicht zu Ketten. Die grüne Färbung läßt Eisgebirge nicht ahnen. Immerhin erkennen wir sanftere Hügel im Mittelland, Rundbuckelreihen im Jura, einzelne Steilwände in den Alpen. Wohl biegen sich die Alpen im Kranz um die flache Poebene; doch treten die Hochalpen nicht zutage. Sie unterscheiden sich zuwenig vom Jura, obschon die Anzahl der Anhöhen in den Alpen am größten ist. Die Rhone fließt zwischen zwei Gipfelreihen hin; Graubünden ist ein Chaos von Bergen.

Benennungen sind spärlich. Der Jura als Ganzes heißt «Blauwen»; auch der «Schwartzwald» ist angegeben. Beim Gotthardgebiet steht «Alpes Leopontij», bei den Bündner Alpen «Alpes Rhaetiae», bei den Walliser Alpen «Alpes Greij». Einzelgipfel sind nicht benannt, es sei denn, sie stellten einen $\mathrm{Pa}$ dar: nämlich «Adula» (Gotthard), östlich davon der steile «Krispalt», noch weiter östlich der niedrigere «Gungulß», westlich vom Tessin der «Mon Jubet», außerdem im Waadtland der «Jurthen» (Mont Jorat) und im Jura der «Wasserfall». Es ist die Wasserfalle am Paßwang und bedeutete damals diesen Paßweg, der von Balsthal und Mümliswil ins Tal der Lüssel und zur Birs hinüberführte. Felix Platter erwähnt den Weg über die Wasserfälle, wo er in seiner Selbstbiographie berichtet, wie er 1562 mit seinem Vater, mit Frau und Schwiegervater von Basel ins Wallis 
ritt. Als weitere Paßnamen finden wir bei Türst «Grimsel» und «Furgen» und «Gemmi», außerdem «Ammenberg» als Übergang von Weesen nach Neßlau im Toggenburg. «S. Bernhartzberg» sieht aus wie ein Dorf auf einem Berge. Am Vierwaldstättersee sind namenlos Mythen und Rigi angedeutet, am Zürichsee die Wölbung des Uetlibergs. Die Anhöhen sind oft nur in Verbindung mit Ortsbildchen zufällig wiedergegeben. So liegt die Grasburg auf ihrem Hügel, Signau an seiner Halde, Engelberg im Kessel zwischen waldigen Hängen.

$\mathrm{Zu}$ erklären bleiben die Namen Krispalt, Gungulß und Mon Jubet. Mit Krispalt ist nicht der Crispalt als Bergstock in der Gruppe des Piz Giuf gemeint, sondern der Paßübergang von Uri nach Bünden, entweder der Oberalppaß, der vom Urserental, oder der Krüzlipaß, der vom Maderanertal in den obersten Abschnitt des Vorderrheintales, ins Tavetsch, hinüberführt. Das Maderanertal heißt bei Türst «Kercheren», das Tavetsch heißt «Davetsch». Der Gungulß ist der Kunkelspaß, über den man von «Ragatz» und «Pfefers» auf geradem Wege nach «Domins» (Tamins) hinübersteigt. Der Mon Jubet heißt nach dem italienischen Gipfel Monte Giove, der sich westlich über Formazza erhebt. Hinter ihm vorbei führt der Pfad des Albrunpasses von Fiesch im Oberwallis ins Val Devero und ins Eschental. Türst nennt die Endpunkte «Viesch» und «Daweder» (was freilich eher das Val Divedro sein kann und dann mehr zum Simplonweg gehört). Der Albrun war der wichtigste $\mathrm{Pa} \beta$ des Oberwallis, neben dem Griespaß der Handelsweg zwischen Berner Oberland und Eschental. Über den Albrun waren 1425 die Berner und Solothurner den in Domodossola umzingelten Bundesbrüdern zu Hilfe geeilt. Somit bedeuten alle Benennungen, die man auf einzelne Gipfel beziehen möchte, letztlich Pässe.

\section{Ortsbildchen}

Kein Zweifel, daß Türst an sehr vielen Orten selber gewesen ist. Dies beweisen seine immer wieder anders gestalteten Ortsbildchen. Heute noch lassen sich die wiedergegebenen Städte und Burgen erkennen, und je mehr man sie mit alten Stichen vergleichen könnte, um so besser sähe man, was er darstellte. Er scheint auf seinen Wanderungen ein Skizzenheft bei sich getragen zu haben, worin er den Eindruck, den Schattenriß der Ortschaften festhielt. Wohin man blickt, von Domodossola bis Rottweil, von Hohentrins bis Pontarlier, sind die Ortsbildchen dem Gegenstand entsprechend gestaltet. Mit wenigen Strichen traf er das Wesentliche. 
Die Zürcher erkennen ihr Großmünster, ihre Fraumünsterkirche und dazwischen den Turm der St.Peterskirche, wie man sie von Westen sieht. Sie entdecken in Kappel die Klosterkirche mit ihrem Dachreiter, am Greifensee die Burg Uster auf ihrem Hügel, am Zürichsee die Schlösser Rapperswil und Pfäffikon. Hoch über Wallenstadt erscheint links auf steilspitzem Berge die St.Georgskapelle von Bärschins.

Dem Rhein entlang begegnen uns das mittelalterliche Konstanz, das burggekrönte Stein am Rhein, Schaffhausen in seinen Mauern, die Klosterkirche von Rheinau, das zum Fluß herabsteigende Kaiserstuhl. Im Wehntal stehen Regensberg am Hügel und die Kirche von Dielsdorf drunten im Tal. Über Baden schreibt Meyer von Knonau, man sehe es von Norden mit dem das Brugger Tor überragenden, auch damals zerstörten Schloß auf dem Stein. Lenzburg verteilt sich auf Hügel und Tal. Westwärts folgen Aarau, Aarburg, Solothurn, dann Büren mit der Wallfahrtskirche darüber, Biel mit seinen Befestigungstürmen. Nidau sehen wir von Süden, Erlach am Steilhang. Cudrefin am Neuenburgersee ist ohne Namen, aber kenntlich gezeichnet. Am Murtensee trotzt das geschlossene Viereck von Murten. Von fern grüßt auf seinem Hügel der Rundturm von Romont. An den beiden Ufern der Saane horstet Freiburg mit den Wehrtürmen und den gotischen Zinken des Münsters.

Mit Freude gewahrt der Berner das Bild seiner Stadt (siehe Abb. 3). Zuoberst steht das Rathaus, wie es heute noch aussieht, nur daß Türst es gegen Nydegg wendet. Daneben ragt der Münsterturm mit dem Baukran darauf. Unten gegen die Aare zu steht die Nydeggkirche, jenseits des Flusses der Torturm. Südlich der Stadt blickt Schloß Bubenberg über den Hügel; westlich dehnt sich in Bümpliz groß das Schloß des Gönners voN Erlach, für den Türst die Karte zeichnete. Der Bremgartenwald ist als «Premgarten» mit fünf Tannen vertreten. Gut unterschieden sind die Umrisse von Thun und von Burgdorf («Burtolff») mit ihren Schlössern. In Kirchberg sitzt die Kirche auf ihrem Hügel. Schloß Brandis und das Truber Kirchlein erinnern an die Freiherren und an das von ihnen gestiftete Kloster.

Zwischen Cham und Risch springt heute noch ein Nagelfluhfelsen gegen den Zugersee vor und trägt Schloß Buonas. Schon bei Türst beherrscht es die Lage; dazu schreibt er jedoch Hertenstein, den Namen der Luzerner Familie, die es besaß. Luzern steigt mit seiner Umgürtung hinter einem Hügel hervor. Ob Sachseln erscheinen vor dem Waldrand Kapelle und Klause des Bruders Klaus, der 1487 gestorben war. 
Aber auch St. Gallen mit seiner Mauer und den hohen Kirchtürmen, Chur mit dem Bischofssitz und der Domkirche, Sitten mit zwei Burghügeln und der Kathedrale sind dargestellt, der Turm von Brig, das Kirchlein von Naters.

Meyer von Knonau, der uns bei diesen Angaben leitet, hat auch die schwäbische Gegend betrachtet. Jenseits des Bodensees ragt der Burghügel von Meersburg über dem gleichnamigen Städtchen empor; die Anhöhe von Heiligenberg senkt sich zum Kloster Salmannsweiler, und weiter gleitet das Gelände ab nach Überlingen. Bei Radolfzell («Zell») mündet in den Bodensee die von Norden heranfließende Aach; an ihrem Lauf erheben sich rechts der spitze Kegel des Hohenkrähen («Kreyen») und die breite Kuppe des Twiel. Vom Rhein bis zur Donau folgen sich die Hegauburgen Rosenegg, Stauffen, Randegg, Stoffeln, Hewen; an der Donau erhebt sich Fürstenberg, und drüben, schon östlich des Neckars, in der Grafschaft Hohenberg, thront die Burg «Forn » auf dem Kegel des Hohenzollern über dem Städtchen Hechingen.

\section{Paßübergänge}

Wenn auch die Straßen nicht eingezeichnet sind, erkennt man doch Türsts Reisewege an der Kette der Ortschaften, die er berührt hat. Es ist reizvoll, an ihrer Hand den Pfaden zu folgen, die er beschritt. Ich werde im folgenden die alten Dorfnamen brauchen. Namentlich im Gebirge ist die Karte aus Straßenzügen entstanden. Klar hebt sich der Gotthardweg heraus. Von Flülen und Altorf, vorbei an der Burg Attichhusen, steigen wir die Rhüß hinan nach Silinen, Wasnen und Geschingen (Göschenen), betreten die Teufelsbrücke, kommen nach Urseren (Andermatt) und Hospital und erreichen das Hospiz auf der Höhe des Gotzhart. Drüben schreiten wir abwärts nach Oerielsß. Am malerischen Engpaß der Talstufe des Glattifer (Plattifer, Monte Piottino) verschwindet der rauschende Tisin kurz hinter einem Felsvorsprung. Wir erreichen Pfeud und überschreiten die Brücke von Irnes.

Auch die seitlichen Zutritte ins Urserental sind gegeben: aus dem Wallis von Brig aufwärts nach Naters, an Erne und Viesch vorbei nach Münster, über Wald und Geschingen (Geschinen und Oberwald, die vertauscht sind) hinauf zur Furgen und über Realp nach Hospital. Auf der andern Seite kommt von Graubünden der Weg über die Oberalp heran, von Inlantz über Disitis (Disentis); südlich davon sind die abgeschiedenen Hütten von 
Medels. Weiter geht es nach Davetsch (ins Tavetsch) und nach Urseren.

Der Simplonpaß führt von Brig nach Domodossola; auf Zügen ins Eschental hatten ihn die Eidgenossen begangen. Türst steigt hinan und erreicht bald schon Sümpelen (Simpeln). Wenn man einen Bergkamm, der sich von Westen vorschiebt, umwandert, erscheint das im Süden liegende Thum (Domodossola). Weiter gegen Süden zu käme man nach Vigmen (Vogogna) und endlich nach Oron (Arona) am Lugarner Seuw, dessen Ufer am Kartenrand eben noch auftaucht.

Den Bernern war die Verbindung zum Wallis über zwei Pässe möglich: Gemmi und Grimsel. Von Thun und Spietz reiste man durchs Tal der Cander aufwärts nach Frutingen (wo man über dem Dorf die Tellenburg erblickte), gelangte zum Dorf Cander (Kandersteg) und über die Gemmi nach Bad (Leukerbad) und hinunter nach Loeg (Leuk), wo der Rhotten vorbeifloß. Oder man zog über Undersewen und Hinderlappen (Interlaken) zum Brienzersee und nach Briens, vorbei an der Kirche von Hasle (Meiringen) und weiter nach Guttenthann, worauf man über das Joch der Grimsel den Rhotten an seiner Quelle erreichte. Von dort konnte man sich durch das Oberwallis nach Brig hinunter begeben oder aber weiter über den Griespaß unmittelbar südwärts ins Eschental hinübersteigen: zwischen Geschingen und Wald klimmt man aufwärts und kommt nach langer Wanderung am Mon Jubet vorbei über Valldösß und Bomnat nach Thum. Valldösß bedeutet Valle d'Ossola, das Eschental; Bomnat (Pomat = Formazza) wäre das oberste Dorf. Sebastian Münster und Johannes Stumpf erwähnen den Griespaß in ihren Hauptwerken. Zwischen Griespaß und Simplon liegt der Albrun.

Als wichtigster $\mathrm{Pa} \beta$ im Westen leitet der Große Sankt Bernhard vom untern Ende des Wallis nach Aosta hinüber. Nach der heutigen Karte tritt man von Martigny ins Tal der Drance ein; dem mittleren ihrer drei Quellbäche entlang steigt man durch das Val d'Entremont langsam zum Hospiz hinan, worauf der Pfad steil ins Aostatal absinkt. Bei Türst stellt sich dieser Weg so dar: Von Martinach gelangt man hinauf nach S.Brancery (Sembrancher). Die Drance hat er nicht gezeichnet. Nun zieht man talein nach Orschen (Orsières) und wendet sich westwärts (in Wirklichkeit ostwärts) nach Burgum S.Petri (Bourg St.Pierre). Dort stehen wir dicht vor dem S. Bernhartzberg und wandern jenseits hinab nach Caesar Augusta (Aosta) im Ougstdal. Dieses wird entwässert durch einen Fluß, der am westlichen Kartenrande verschwindet, während er in Wahrheit nach Osten und dann 
nach Süden strömt. Am Fluß folgen die Orte Bartt und Yporegia (Bard und Ivrea). In südlicher Ferne läge Nowerren (Novara).

Der Theodul-Paß, der zwischen Simplon und St.Bernhard die Mitte hält, ist ebenfalls durch Haltestellen belegt. Nach der heutigen Karte strebt der Weg von Visp hinan nach Zermatt und erreicht drüben bei St. Vincent das Aostatal. Türst nennt Vischb, Matt und S. Vicentz. Dieser Ort sollte nahe dem Fluß zwischen Aosta und Bard liegen. Da aber bei Türst jenes Tal nach Westen abgewendet ist, bleibt St. Vincent weit im Nordosten zurück. Diese abgesonderte Lage spricht dafür, daß ihm der Ort als Ende des Pfades über den Theodul, nicht als Station unter dem Ende des St. Bernhardweges vorschwebte. Nahe bei St.Vincent, in der Richtung gegen Domodossola, liegt die Walsersiedlung Grettynoeff (Gressoney).

Wie Meyer von Knonau bemerkt, ist Türst auch über die kleineren Pässe des Mittellandes geschritten. So erkennt man den Weg vom oberen Ende des Toggenburgs hinüber ins Rheintal, nämlich von S.Johans über Wildenhus nach Gams und Werdenberg, oder man beobachtet die Reihe der Orte vom Vierwaldstättersee bis zum obern Zürichsee: von Brunnen über Schuitz (= Schvitz, Schwyz), Steinen, Sattel, Turn (Rothenthurm) nach Pfeffikon und über die Seebrücke nach Rapschuil (= Rapschvil, Rapperswil).

Auch sonst lassen sich Reisewege verfolgen. Man ahnt, wie Türst von Arouv über Kölliken und Zovingen nach S. Urban, Langental und Hutwil gezogen ist. In der Westschweiz gelangte er deutlich von Friburg über Illingen (Illens) und Remund (Romont) nach Rhuw (Rue, deutsch Rüw) und weiter über den Jurthen nach Lausana. Ein andermal streifte er von Morten über Wiblspurg (Avenches) und Betterlingen (Payerne) nach Milden (Moudon) und kehrte von dort nach Ifertun (Yverdon) zurück.

Im Jura ging er durch die Gebirgspforte der Klus. Er verließ Solodrun und kam über Wietlispach, Pipp und Kestinholtz zum Engpaß, wo die Schlösser Bechburg und Falkenstein auf die «Clusen» herniedersahen. In Balstal spaltete sich der Weg. Nach rechts konnte man nach Schöntal (Kloster bei Langenbruck) wallfahrten und das Städtchen Walenburg (Waldenburg) besuchen. Nach links stieg man über den Wasserfall (Wasserfallenberg) und entdeckte jenseits die Birs und die Burg Dierstein. Thierstein läge freilich noch am Seitenbach, an der Lüssel; doch wird der Fluß kurzweg als Birs bezeichnet. Der Paßwang oder Wasserfall spielte damals eine Rolle wie heute der Hauenstein, der bei Türst fehlt. 
Gewiß: es ist manches unklar. Da Türst keine Wege eintrug, kann man die Reihenfolge der Orte entlang den einzelnen Pässen - etwa vom Wallis ins Aosta- und Eschental - zwar nach der modernen Karte auf der alten finden; betrachtet man aber Türsts Bild allein, so lassen sich die Wege nur erraten, wenn man sie kennt. Gerade dies aber durfte er bei vielen Zeitgenossen voraussetzen. Die Pässe wurden reger begangen als heute. Der Handel hatte noch keinen Tunnel, keine großen Straßen gefunden. Seit Jahrzehnten bewegte zudem der kriegerische Verkehr mit Mailand die Gemüter. Darum diese Fülle angedeuteter Alpenpässe: Großer Sankt Bernhard, Theodul, Simplon, Albrun, Gries und Gotthard, in den Berner Alpen Gemmi und Grimsel.

Keinen einzigen Berg nannte Türst um seiner Schönheit willen; der Pilatus ist für ihn nicht vorhanden. Aber die Wege über die Berge waren damals vertraut. Mit der Karte blicken wir in jene Zeit: sie spiegelt Schweizergeschichte.

\section{Türsts Karte in Ptolemäus -Ausgaben}

1513 erschien in Straßburg beim Drucker Johannes Schotr eine Ptolemäus-Ausgabe, die außer den 27 Karten des Ptolemäus einen Anhang mit 20 neuen Karten bot. Darunter hieß die siebzehnte «Tabula nova Heremi Helvetiorum » (Neue Karte der Einöde der Helvetier); dieses Wort war aus Ptolemäus geschöpft. Die Karte unterschied sich von den übrigen durch ihre Ortsbildchen und war nichts anderes als ein Holzschnitt nach der Vorlage der Türst-Karte, von der ein Exemplar der lateinischen Fassung zur Verfügung gestanden haben muß. Der Holzschnitt erforderte eine Vergrößerung der Federzeichnungen und Anschriften. Da der Rahmen jedoch durch die Buchgröße beschränkt war, mußte der Holzschneider viele Orte weglassen und die Karte am Rande beschneiden. Er ließ einen schmalen Streifen am Ostrand und breitere Streifen im Süden und Westen beiseite. Seine Karte reicht statt zum Genfersee nur bis Freiburg. Dafür ergänzte er über den untern Rand hinaus Basel, das 1501 der Eidgenossenschaft beigetreten war. Der Maßstab beträgt nach Iмноғs Bestimmung etwa 1:400000 gegenüber 1:500000 bei Türst. Dessen Strecken wurden also um ihren vierten Teil vergrößert.

Als Bearbeiter gilt Martin Waldseemüller, um 1470 in Freiburg im Breisgau geboren, Gymnasiallehrer in Saint-Dié in Lothringen, der 1507 
eine Kosmographie und Weltkarte, 1511 eine Europakarte geschaffen hatte.

Auf die Entfernung wirkt die Holzschnittkarte schmucker, malerischer als ihre Vorlage; bei der nähern Untersuchung erweist sie sich als beträchtlicher Rückschritt. Der Verfasser hatte nichts von Türsts Reisläuferblut, nichts von seiner Sehnsucht nach der Ferne. Es kam ihm auf die Städte an. Was bei Türst ummauert erschien, das nahm er sicher auf. Die Bilder von Konstanz, Zürich, Luzern, Bern und Freiburg vergrößerte er stark, so daß er das Ende des Zürichsees verbreitern mußte und andererseits hinter Luzern der Alpnachersee fast verschwand. Für die Bildchen benützte er vielleicht hie und da noch eine zufällige Vorlage. Імноғ bemerkt, Thun sei im Gegensatz zur Nordansicht bei Türst von Süden her abgebildet, Schaffhausen ebenfalls von Süden mit dem Munot rechts, Zürich vom Sihlfeld her mit St.Peter-Turm und doppeltürmigem Fraumünster. Als erkennbar bezeichnet er Elgg, die Klosterkirche Rheinau, die Kapelle ob Andermatt und den Turm von Hospenthal. Bern ist unkenntlich, sein Münsterturm von phantastischen Erkern umkränzt, das Bürgerhaus mit Straßburger Treppengiebeln geschmückt, eine Zufahrt von Norden erfunden, dagegen die Nydeggbrücke verloren, das jenseitige Tor entschwunden, die Schlinge der Aare gestreckt (siehe Abb.4). Allgemein sind die Bilder wenig getreu, mit Türmen, Toren, Zinnen willkürlich ausgestattet. Die Alpen sind zackiger herausgehoben als der kuppige Jura; dies mag ein Fortschritt sein. Die Breiten $46^{\circ}$ und $47^{\circ}$ sind am Rand bezeichnet; die Längen fehlen, und dies mit Recht.

Von den 521 Namen der Türst-Karte sind 380 aufgenommen. Vielleicht waren bei der Vorlage die Seen nicht koloriert; es ist seltsam, wie der Holzschneider sie wegläßt. Winzig ist der Greifensee noch vorhanden; aber Hallwiler-, Baldegger- und Sempachersee, auch der Bielersee sind vergessen. Der Neuenburger- und Murtensee fallen ohnehin neben den Kartenrand. Auch Fehler kommen hinzu. Linth- und Sernftal sind verwechselt. Der Oberlauf der Emme wurde ans obere Ende der Kleinen Emme angeschlossen. Türst hatte eben «Emmentall» irrtümlich oben an das Entlebuch geschrieben. Waldseemüller muß um die Ortschaften des Emmentals gewußt haben. Daß nun die Reuß sich unter Luzern gabelt und einen Seitenarm durch das Emmental herabsendet, fiel ihm nicht als Fehler auf. Den Damm von Rapperswil schob er vom Städtchen weg gegen das obere Ende des Sees, teils aus Raumgründen.

1520 legte Schott seinen Ptolemäus nochmals auf. Betreuer der Ausgabe 
war wiederum Waldseemüller. Die Schweizerkarte wurde neu gestochen und den andern Karten angeglichen. Ringlein traten an die Stelle der Ortsbildchen. Im Titel ist das Wort «Heremi» gegen «Eremi» ausgewechselt. Die Alpen erscheinen nun als gewaltige runde Buckel, der Jura als viele Hügel, das Mittelland flach. Der Fehler bei den Emmen ist verbessert, Türsts Bild dort wiederhergestellt. Die Ausschaltung der Ortsbilder schuf Platz, und die Karte reicht wieder bis fast zum Genfersee. Die Mittellandseen sind nun alle vorhanden. Türsts Karte stand also noch zur Verfügung, denn das Bild greift von neuem darauf zurück. Seine Fehler (Erlibach im Kandertal, Ober- und Nidersibental als Dörfer im Saanetal, die Mündung der Glatt in die Limmat statt in den Rhein) sind wie 1513 auch 1520 übernommen. Verbessert gegenüber Türst und dem Blatt von 1513 ist Trachselwald, das vom Brienzersee ins Emmental verlegt ist. Türst nennt es in seiner Beschreibung dort; jemand wird bestätigt haben, daß es so sei.

Bereits 1522 wurden die Ptolemäus-Karten abermals unter die Presse gelegt, diesmal bei Johannes Gruninger an der Schlauchgasse, dem fleißigsten Drucker Straßburgs. Er besaß eine eigene Holzschneidewerkstatt, und auch die Schweizerkarte wurde neu geschnitten. Sie nahm das schmucke Blatt von 1513 zum Muster, ersetzte aber die Ortsbildchen durch Ringlein. Die Grenze im Westen ist jetzt wieder Freiburg. Kleine und Große Emme sind wieder verbunden, gehen aber nicht aus der Reuß hervor, sondern unmittelbar aus dem Vierwaldstättersee, der zwei Abflüsse hat. So war die Reußgabelung vermieden und eine der Überlegung entsprungene Scheinlösung erzielt. Der Seearm gegen Stansstad und Alpnachstad, 1513 nur noch zwischen den Giebeln von Luzern sichtbar, ist jetzt übersehen und verschwunden, ein Beleg, daß Türsts eigenes Blatt dem Kopisten nicht mehr vorlag. Die Donau fließt nun zwischen hohen Bergen. Die Alpenspitzen scheinen durch die Fernsicht verkleinert. Als Herausgeber waltete diesmal Lorenz Fries aus Kolmar. Von ihm erfahren wir zum erstenmal, daß Waldseemüller früher die zusätzlichen Karten hergestellt habe.

Eine vierte Straßburger Ptolemäus -Ausgabe folgte 1525 wieder bei Gruninger. Geleitet wurde sie von Willibald Pirckheimer, dem Nürnberger Humanisten. Dann gingen die Druckstöcke nach Lyon. Dort wurden sie noch zweimal verwendet; die Ausgabe von 1535 betreute Michael Servet, die von 1541 Kaspar Trechsel. Die Schweizerkarte wurde immer schlechter wiederholt. Sie verarmte an Inhalt und vermehrte ihre Verzerrungen und Fehler, da viele Namen falsch abgeschrieben wurden.

Die Führung in der Herausgabe des Ptolemäus ging von Straßburg an 
Basel über. 1533 legte hier Erasmus von Rotterdam erstmals den griechischen Urtext vor, und 1540 lieferte Sebastian Münster die Karten, denen er neue beifügte. Um jene Zeit aber hatte Türsts Karte ihren Lauf vollendet. Es erschien 1538 die unabhängig von ihr gestaltete große Schweizerkarte von Aegidius Tschudi, die für den Rest des Jahrhunderts als Vorbild diente. Tschudis Darstellung war nüchterner, aber genauer und reichhaltiger; die Zahl der Namen beträgt 1194, wenn man die lateinischen Beigaben mitzählt.

Durch 25 Jahre, von 1513 bis 1538, hatte Türsts Karte allein der Öffentlichkeit das Bild der Schweiz vor Augen gestellt. Sie war die einzige Vorlage für die ersten gedruckten Schweizerkarten. Keine ihrer Nachahmungen erreichte wieder das Blatt von 1513, geschweige denn das ursprüngliche Vorbild. Dennoch verdienen diese Drucke Anerkennung. Durch sie fand Türsts Karte ein Nachleben, Jahre nach dem Tode ihres Schöpfers.

\section{Literatur}

Theophil Ischer, Die ältesten Karten der Eidgenossenschaft, Bern 1945.

$Z u$ Türsts Leben außerdem:

Richard Feller und Edgar Bonjour, Geschichtsschreibung der Schweiz, Basel/Stuttgart 1962 (Band 1, Abschnitt Türst).

Türsts Text und Karte:

Originalhandschrift und Originalkarte in der Zentralbibliothek Zürich.

Ausgabe von Georg von Wyss und Hermann Wartmann in Quellen zur Schweizer Geschichte, Band 6, Basel 1884 (mit einem Verzeichnis der Namen auf Türsts Karte).

Korrekturen dazu: Frutingen (ng), Grettynoeff (statt Preiry noeff).

Zur Kartenbeschreibung:

Gerold Meyer von Knonau, Die älteste schweizerische Landkarte. Jahrbuch des Schweizer Alpenclub, 18. Jg., Bern 1883.

EduARd ImHof, Die ältesten Schweizerkarten, Zürich 1939 (Begleittext zu einer Neuausgabe der Karte von 1513 mit Untersuchung der geometrischen Eigenschaften der TürstKarte).

Geographisches Lexikon der Schweiz (z.B. Crispalt, Griespaß, Piottino) sowie Historischbiographisches Lexikon der Schweiz (z. B. Albrun).

Bruno Messerli, Die Frage der ältesten gedruckten Schweizerkarte. Jahresbericht XLVI (1961/62) der Geographischen Gesellschaft von Bern (mit kleinen Abbildungen der Schweizerkarten von 1513, 1520 und 1522). 